\title{
Editorial
}

\section{WHY ARE WASTE MANAGEMENT FACILITIES SO UNATTRACTIVE?}

Waste Architecture is a branch of the design field relating to the Architecture and Land Planning of waste management and disposal facilities based on projects ranging from a vast (landfills, incinerators, treatment plants) to a municipal and peri-municipal scale (waste collection systems, recovery and recycling plants, etc ...).

This branch therefore deals with works and products featuring a marked environmental, territorial, economic and social impact, a topic towards which Society is known to be highly sensitive. The issue therefore dictates a need for targeted political and planning strategies aimed at increasing awareness of the importance of these structures in ensuring quality of the environment and the territory, which may also produce major repercussions on our health. Health intended, according to the WHO definition, as "a state of complete physical, mental and social well-being" achieved through the actual and perceived quality of the space within which one lives.

Waste management is a topic that actively impinges on society, although frequently associated with clichés and misleading persuasions that result in the infrastructures present throughout the network being viewed as areas of neglect, environmental and territorial eyesores to be placed on the margins of shared community spaces.

The demographic increase and scarce availability of space have both resulted in landfills, incinerators, treatment plants and integrated waste disposal systems becoming an integral part of our daily routine. Whilst in the past similar issues were viewed as technical aspects of Engineering, the current need to include these works in a detailed land planning has highlighted a requirement in the fields of landscape and urban design to rely on a multidisciplinary team that extends to the area of Architecture.

In the specific context of wastes, with very few rare exceptions, architects are however inexplicably excluded from the conception, planning and development of these key infrastructures.

On the whole, the majority of nations worldwide fail to envisage an integration between the waste management system and the territory throughout which the system operates. This criticality is largely due to lack of recognition of the role of primary urban infrastructure, i.e. an essential service in the life of a Community. The waste system, in the same way as other infrastructures comprising hubs and networks, is linked to a need for works and interventions for which (with very few exceptions) no planning aimed at ensuring integration with the landscape (natural and urban) is envisaged, nor architectural research to promote manufacturing quality of the goods.

In common practice, architectural techniques for the collection and treatment of wastes are designed as highly efficient industrial products. Technical and functional requirements that frequently dictate the form of these works thus evolve into overt limitations that hamper the potential configurations, with functional needs rarely being supported by architectural and manufacturing studies.

Indeed, many of the works undertaken are conceived based exclusively on technical aspects, with negative architectural and social implications. The majority of plants adopted by the "waste system" have tended to create feelings of threat, diffidence and hostility, thus frequently being considered an unnecessary "evil" to be eliminated or hidden from view (think of landfill constructed in the past, with the black fumes rising from the heaps of waste and of the incinerator chimneys).

Viewed to date by politics as a "problem" rather than a resource, by communities as a threat, by environmentalists as an endless source of pollution, by sanitary engineers as functioning machines and by architects as works in which design is limited merely to the packaging, the infrastructure hubs throughout the waste collection network have struggled to achieve any form of "dignity" as public works, although being of fundamental importance for modern-day society.

Accordingly, the inescapable role covered by the waste management network should be acknowledged in the same way as other public services (transport, water supply, lighting, etc.), and all associated works undertaken with the same attention to details of planning and design devoted to any other works of community concern in terms of planning, siting, study of the context, choice of shapes and material, legibility of spaces, levels of planning and design, economic analysis. And, in the same way as planning for all major works (ranging from bridges to skyscrapers, from museums to airports ...), the technical requirements will need to adapt to the architectural needs rather than the contrary.

Numerous works undertaken throughout the world, from the Ariel Sharon Park on the Hiryia landfill in Israel, to the Val d'en Joan in Barcelona and the Amarger Bakke incinerator in Copenhagen, have demonstrated how this type of architecture constitutes a highly interesting sector that highlights, throughout the various stages of the project, a series of potentials: the recognisability of the structures may be exploited to characterise a landscape or a city; a 
high-quality architectural project will contribute towards enhancing legibility with a view to raising environmental awareness and may provide an opportunity to create new functionalities; degraded areas may be restored to a new vocation.

Based on these considerations, and with a view to "ennobling" this sector, in 2015, Arcoplan Associates devised the Waste Architecture Platform, a showcase for initiatives that has brought together environmental experts, architects, designers, urban and land planners to encourage networking on an international level on the topics of mutual interest in seminars, design workshops, publications, etc. Since then, Arcoplan has been consistently involved in the organisation of oral sessions at the prestigious Sardinia - International Waste Management and Landfill Symposium, a reference event over the last 30 years for the scientific community that rotates around waste, thus rendering Waste Architecture one of the main topics of the Symposium.

This monographic issue represents one of the outputs of the Waste Architecture Platform, providing a selection of papers presented during the third edition of the Internation- al Workshop on Waste Architecture / Landscape and urban areas, held in October 2019, listing in the final columns the results of the design workshop focused on the redevelopment of landfills scheduled on the second day of the event. The Workshop was organised by Arcoplan Associates with the scientific support of ReLOAD Lab / ICEA - Department of Civil Environmental and Architectural Engineering, University of Padova (IT).

The issue moreover includes a series of external contributions from designers working in the specific field on both an academic and professional level.

It is to be hoped that the planning and design of key infrastructures in the waste sector such as those described in the papers present in this monographic issue, with their ability to conjugate environmental requirements with care for the territory, high quality architecture and wellbeing of the community, will gradually start to be provided for as a matter of routine.

Anna Artuso, Elena Cossu Arcoplan Associates, Italy studioarcoplan.it

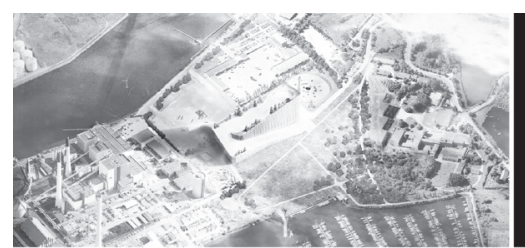

WA

WASTE ARCHITECTURE PIATEORN/L
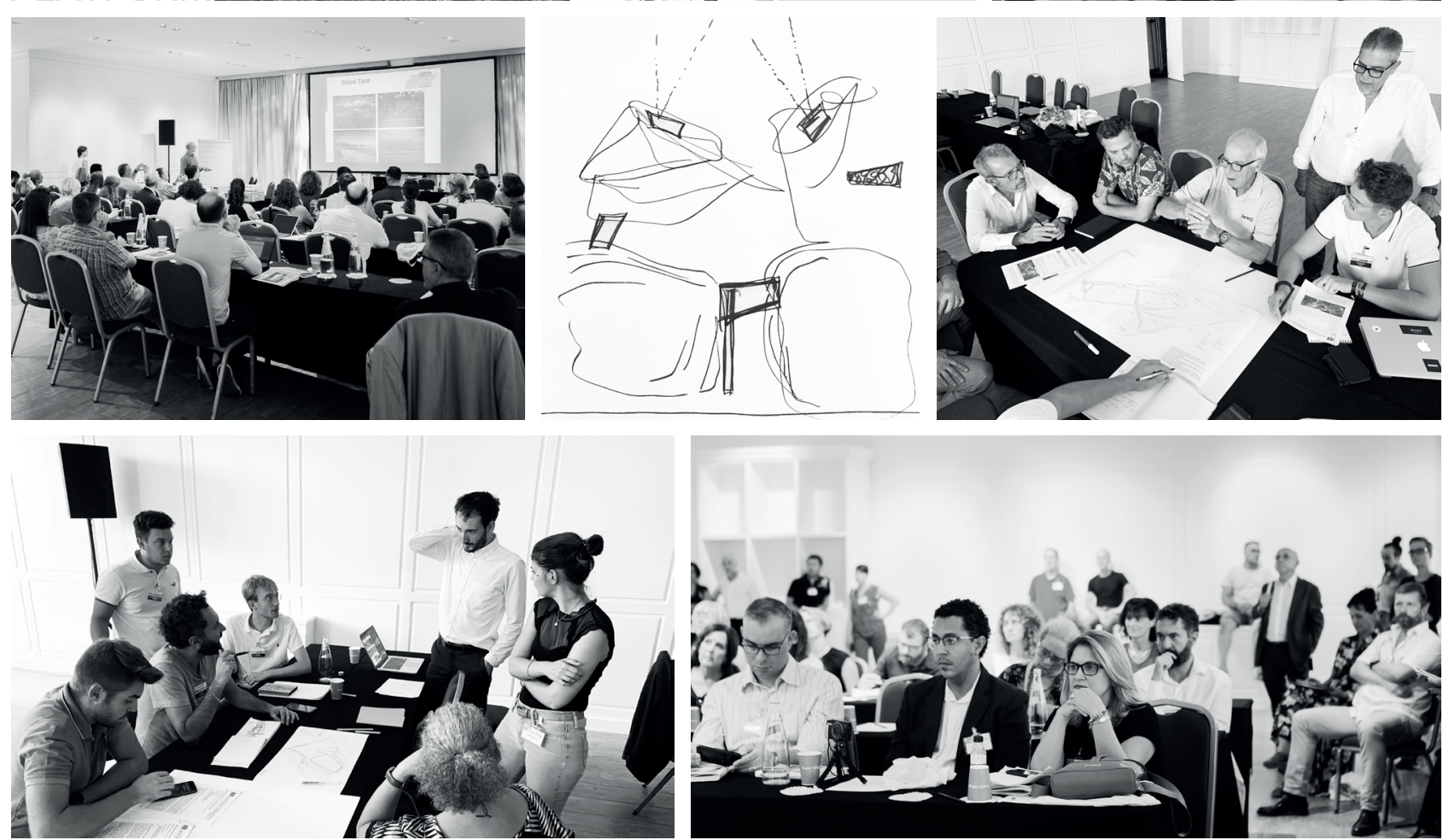

INTERNATIONAL WORKSHOP ON WASTE ARCHITECTURE 1-2 OCTOBER 2019 ORAL SESSIONS + DESIGN LAB
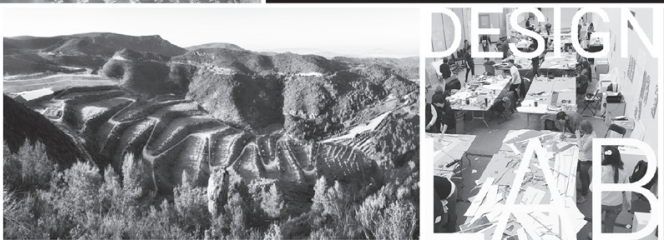

sardinia

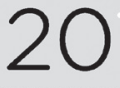

17TH INTERNATIONAL WASTE MANAGEMENT AND LANDFIL
SYMPOSIUM/ / /CAGLIARI (IT)
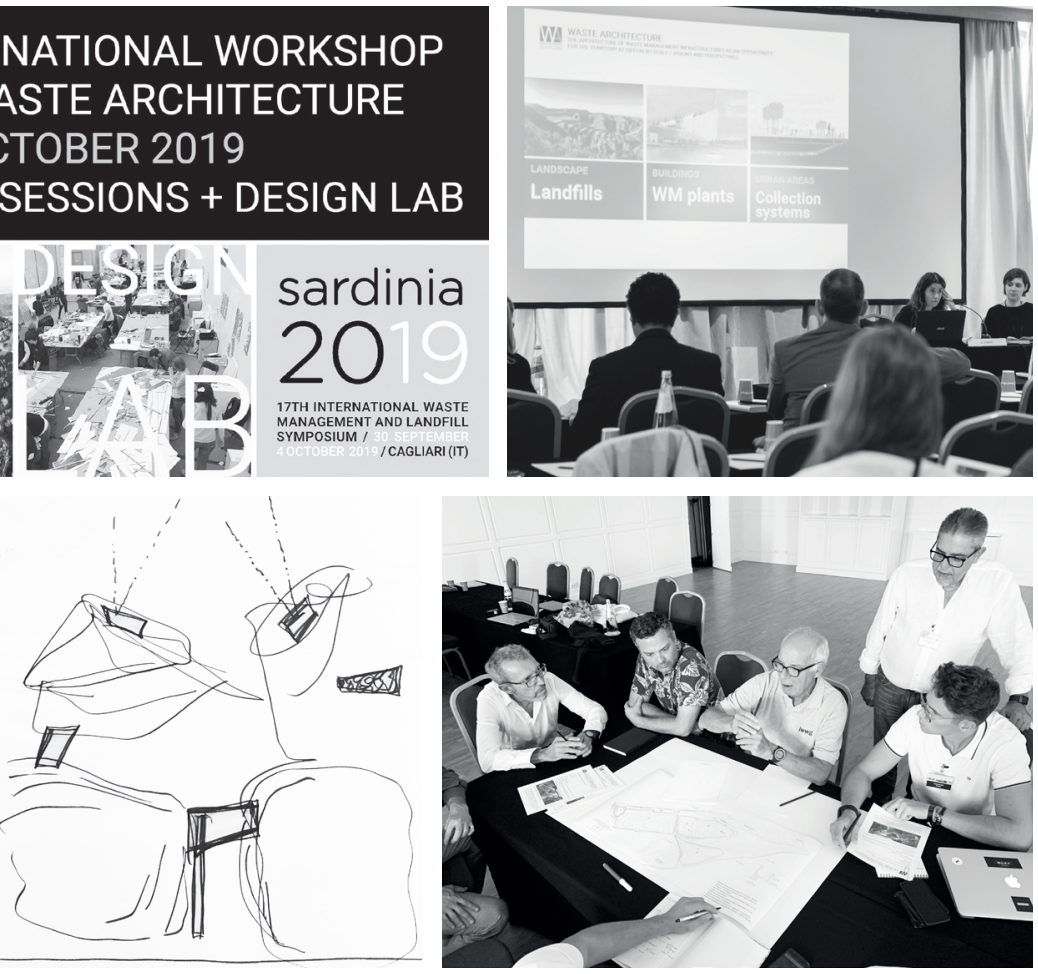

A. Artuso, E. Cossu / DETRITUS / Volume 11 - 2020 / pages 1-2 